Check for updates

Cite this: Mater. Adv., 2021, 2, 754

Received 5th November 2020, Accepted 7th December 2020 DOI: $10.1039 / \mathrm{d} 0 \mathrm{ma} 00860 \mathrm{e}$

rsc.li/materials-advances

\title{
Solution-processed ITO nanoparticles as hole-selective electrodes for mesoscopic lead-free perovskite solar cells $\dagger$
}

\author{
Donghoon Song, ${ }^{a}$ Liang Yu Hsu, ${ }^{a}$ Chien-Ming Tseng ${ }^{a}$ and \\ Eric Wei-Guang Diau (ID *ab
}

\begin{abstract}
Carbon-based mesoscopic perovskite solar cells (PSCs) are promising for printable next-generation photovoltaic applications, but the optical properties of their carbon layer limit their light harvesting efficiency. We developed solution-processable indium-tin-oxide (ITO) nanoparticles to replace carbon electrodes for mesoscopic lead-free tin-based PSCs. The ITO electrodes were fabricated via screen printing with 1, 2, 4, 6 and 8 layers corresponding to the thicknesses of 2.1-14.3 $\mu \mathrm{m}$; tin perovskite $\left(\mathrm{GA}_{0.2} \mathrm{FA}_{0.8} \mathrm{Snl}_{3}\right.$ ) with $\mathrm{SnF}_{2}(20 \%)$ and $\mathrm{EDAl}_{2}$ (15\%) (GA represents guanidinium; $\mathrm{EDAl}_{2}$ represents ethylenediammonium diiodide) was drop-casted on the device to produce a mesoporous structure of $\mathrm{FTO} / \mathrm{TiO}_{2} /$ perovskite/ $\mathrm{Al}_{2} \mathrm{O}_{3} / \mathrm{ITO}$. The best device achieved a power conversion efficiency of $5.4 \%$ with great stability. These solution-processed ITO electrodes are a landmark to shed light on new paths for the commercialization of lead-free PSCs.
\end{abstract}

\section{Introduction}

Solution-processable perovskite solar cells (PSCs) have attracted much attention because of their recent rapid progress in propelling the efficiency to $25.2 \%$, near that of silicon SC, ${ }^{1-8}$ but PSCs face two major issues: toxicity and limited scalability. The toxicity arises from lead in the perovskites. Possible elements to replace lead include tin, copper, germanium, antimony and bismuth. ${ }^{9}$ Among them, tin enables the best performance of perovskites benefiting from a large absorption coefficient, large charge carrier mobility and an ideal tunability of the band gap. ${ }^{9}$ Such tin-based perovskites have been extended to other applications such as transistors, ${ }^{10}$ photodetectors ${ }^{11}$ light-emitting diodes ${ }^{12}$ and lasers. ${ }^{13}$ For highperformance PSCs, tin perovskites have evolved by suppressing the oxidation of tin (from $\mathrm{Sn}^{2+}$ to $\mathrm{Sn}^{4+}$ ), pinholes and surface defects while improving the crystallinity through an exploration of hybrid cations or anions, ${ }^{14-23}$ additives ${ }^{24-33}$ and interfacial engineering. ${ }^{34-37}$ The additive approach is effective regardless of the type of tin perovskite and its interfaces. Beyond the addition of tin fluoride $\left(\mathrm{SnF}_{2}\right),{ }^{24}$ the incorporation of ethylenediammonium diiodide $\left(\mathrm{EDAI}_{2}\right)^{25,26}$ into tin perovskites makes them efficient. A distinct

\footnotetext{
${ }^{a}$ Department of Applied Chemistry and Institute of Molecular Science,

National Chiao Tung University, 1001 Ta-Hsueh Rd, Hsinchu 30010, Taiwan. E-mail: diau@mail.nctu.edu.tw

${ }^{b}$ Centre for Emergent Functional Matter Science, National Chiao Tung University, 1001 Ta-Hsueh Rd, Hsinchu 30010, Taiwan

† Electronic supplementary information (ESI) available. See DOI: 10.1039/ d0ma00860e
}

feature is that hollow 3D perovskites with high performance emerge with $\mathrm{EDAI}_{2}$ at a large proportion. ${ }^{26}$

Carbon-based mesoscopic PSCs are highly promising because of all-solution-processing based on screen printing and drop casting. ${ }^{38,39}$ These processes are additive, allowing minimal waste of valuable materials, in striking contrast with the laboratory-scale PSCs fabricated with subtractive processes including spin-coating and thermal evaporation that significantly waste valuable materials. In addition, carbon is robust and could serve as an electrode with no need of hole-transport materials (HTMs) to avoid a device instability caused by HTMs. ${ }^{39,40}$ Despite the great promise, the best performance of carbon-based tin PSCs resides at $4.22 \%,{ }^{19}$ whereas the efficiency of planar tin PSCs is aggressively evolving over $9 \% .^{14,15,27,28,32-34,41}$ One reason is that carbon does not reflect visible light, unlike Au or Ag in planar PSCs, ${ }^{39}$ and suffers from poor hole selectivity because of the rapid charge recombination, thereby limiting significantly this otherwise promising technology.

Indium-tin-oxide (ITO) films, sputtered or solutionprocessed, are widely used in diverse applications including solar cells. ${ }^{42}$ While the sputtered ITO is a flat film type, the solution-processed ITO comprises ITO nanoparticles of $<50 \mathrm{~nm}$ in diameter. Both ITO electrodes serve as transparent electrodes, coupled with HTMs for semitransparent or tandem perovskite solar cells, due to the large band gap and have never been used as light reflective electrodes in PSCs. If the size of ITO nanoparticles are increased in diameter to $50 \mathrm{~nm}$ or larger, 
they can reflect visible light according to the Mie theory. ${ }^{43,44}$ The excellent compatibility of ITO as an HTM-free electrode with tin perovskites and tin-lead perovskites has been reported. ${ }^{45,46}$ In this work, we replaced the carbon electrodes with solution-processed ITO nanoparticulate electrodes to produce mesoscopic lead-free tin PSCs. Fabricating highly porous but mechanically stable and conductive ITO films constituted the key challenge.

\section{Results and discussion}

We first formulated a screen-printable ITO ink by milling them with the ink components including ethyl cellulose, terpineol and poly(ethylene glycol) (PEG) in the presence of ethanol (see detailed processes in ESI $\dagger$ ). PEG helped to improve the conductivity and stability of the resulting films ${ }^{47}$ while the excess amount of ethyl cellulose enabled to increase the porosity. The formulated ITO ink was then screen-printed and annealed at $400{ }^{\circ} \mathrm{C}$ for $30 \mathrm{~min}$. For multiple layers, the printing was performed 1, 2, 4, 6 and 8 times to generate layers of thicknesses $2.1,4.2,8.3,12.2$ and $16.2 \mu \mathrm{m}$, respectively. As shown in Fig. S1a-c, ESI, $\dagger$ the ITO films possessed the signature characteristics including a work function of $4.7 \mathrm{eV}^{48}$ and surface states characterized with X-ray photoelectron spectroscopy (XPS); both the characteristics are drastically tunable enabling a broad range of applications. The ITO electrode work function is smaller than that $(\sim 5.0 \mathrm{eV})$ of the carbon electrode, but might be better compatible for hole extraction with tin-based perovskites that are shallower in energy levels (valence band maximum, VBM: $\sim 4.8-5.2 \mathrm{eV}$ ) than the lead perovskites (cf. $\mathrm{VBM}$ of $\left.\mathrm{MAPbI}_{3}: \sim 5.4 \mathrm{eV}\right){ }^{49}$

Fig. 1a and Fig. S1d (ESI $\dagger$ ) show the resulting films in low and high magnification views, respectively, in which the ITO NPs are 3D-interconnected due to the annealing that removes the organic components while enabling tight bonding between the ITO NPs and leads to a massive decrease in the sheet resistance from $>10^{8} \Omega \mathrm{sq}^{-1}$ to $<2 \mathrm{k} \Omega \mathrm{sq}^{-1}{ }^{-1}$ : it drops from $1600 \pm 250$ to $118 \pm 4 \Omega \mathrm{sq}^{-1}$ with increasing thickness (all the numerical values are listed in Table $\mathrm{S} 1, \mathrm{ESI} \dagger)$; the obtained sheet resistances are comparable to that $\left(\sim 30-1300 \Omega\right.$ sq. $\left.^{-1}\right)$ of the highly transparent ITO nanoparticulate electrodes, ${ }^{50-52}$ but our ITO is distinct regarding porosity and light selectivity (see more discussion in the following). The films have sufficient porosity $(\sim 70 \%$ estimated from the weight measurements of total volume and solid ITO volume) for perovskite infiltration, a crucial step towards high performance of the mesoscopic PSC. Fig. $1 \mathrm{~b}$ shows the size distribution of the ITO NPs (average diameter $\sim 70 \mathrm{~nm}$ ), enabling light reflection over a wide visible region as demonstrated in Fig. 1c.

The optical properties systematically altered with the thickness of the ITO film. For example, a thick ITO film lost transparency of visible light manifested as a faded logo (Fig. 1d). This effect is a result of increased light reflection, as presented in Fig. 1e. Specifically, the thicker the ITO film (from 2.1 to $16.2 \mu \mathrm{m}$ ), the more enhanced the visible reflectance ( 37 to $66 \%$ at the maximum), concurrent with a shift to longer wavelength (from 434 to $516 \mathrm{~nm}$ )
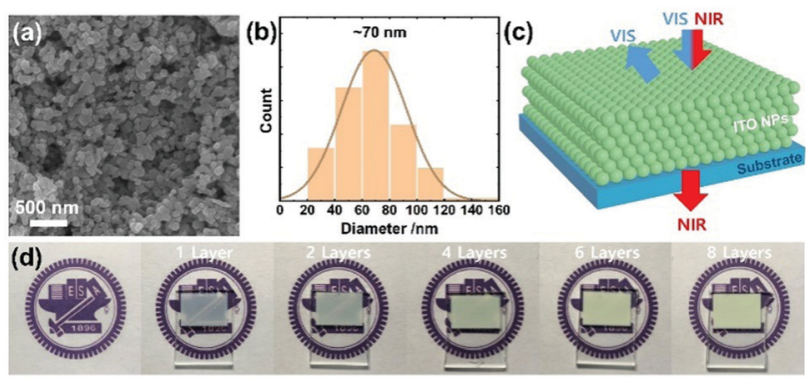

Diameter $/ \mathrm{nm}$
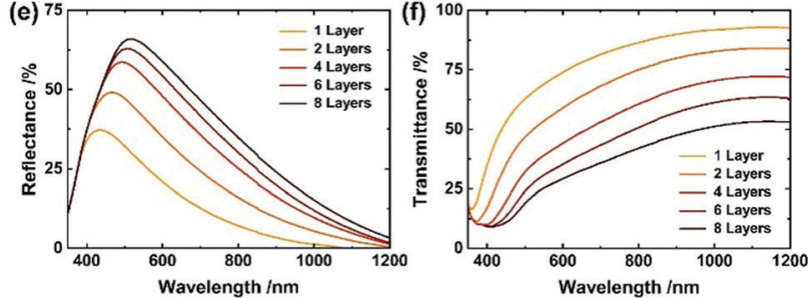

Fig. 1 (a) SEM image and (b) size distribution of ITO nanoparticles in this research. (c) Illustration showing light-selective properties of an ITO nanoparticulate electrode, which is simplified from the data shown in (e and f). (d) Optical images of ITO electrodes showing decreasing visibility of the logo with increasing layers (i.e. thickness). (e) Light reflectance and (f) transmittance spectra depending on the thickness of the ITO electrodes.

(see Table S1 (ESI $\dagger$ ) in which characteristic values are listed). To understand these results, we performed an optical simulation (the corresponding results appear in Fig. S2a, ESI $\dagger$ ) that shows large ITO NPs (diameter near $140 \mathrm{~nm}$ ) to possess improved efficiency of reflection of visible light while shifting the reflection to a greater wavelength. As a thicker film contains more number of large ITO NPs, these simulation results account for the enhanced and shifted properties exhibited in Fig. 1e. In contrast, large reflectance of 16, 29, 42, 48 and 53\% for 1, 2, 4, 6 and 8 layers at $650 \mathrm{~nm}$, respectively, was demonstrated, implying light harvesting in the entire visible region. The striking difference of the ITO nanoparticulate electrodes from the classical electrodes such as $\mathrm{Ag}$ or $\mathrm{Au}$ is that the reflection co-exists with the near-infrared transmission $(93,84,72,63$ and $53 \%$ at $1150 \mathrm{~nm})$ that increases with the decreasing thickness of the film (Fig. 1c and f). Such light properties would be desirable for tandem applications such as PSC/PSC or PSC/photodetector for near-infrared sensing. It is likely from the simulation result in Fig. S2b (ESI $\dagger$ ) that the bigger particles $>\sim 200 \mathrm{~nm}$ would aggressively reflect the near-infrared light so as to eliminate the unique promising property.

We fabricated the mesoscopic PSC by sequentially screenprinting the mesoporous $\mathrm{TiO}_{2}$ (electron transport layer), $\mathrm{Al}_{2} \mathrm{O}_{3}$ (insulating layer) and ITO (HTM-free electrode) scaffolds and infiltrating the perovskite with drop-casting (further details in ESI $\dagger$ ). In Fig. $2 a$, the final device is shown schematically, based on an image from the scanning electron microscope (SEM) to visualize the perovskite completely infiltrated into the $\mathrm{TiO}_{2} /$ $\mathrm{Al}_{2} \mathrm{O}_{3}$ scaffolds, which is further supported with optical images in Fig. 2b. As schematically drawn in Fig. 2c, the infiltrated perovskite crystal is based on the hybrid cation ${ }^{41}$ of formamidinium (FA, $80 \%)$ and guanidinium (GA, 20\%) with additive $\mathrm{SnF}_{2}(20 \%)$ and co-additive $\mathrm{EDAI}_{2}(15 \%)$ according to the optimal performance of 
(a)

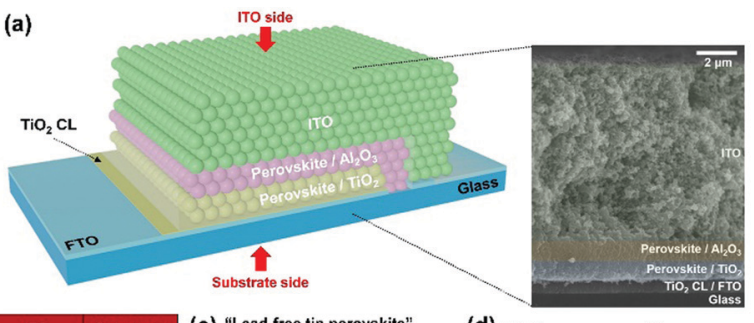

(b)

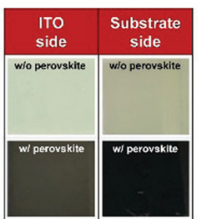

(c)

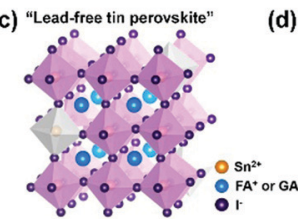

(e)
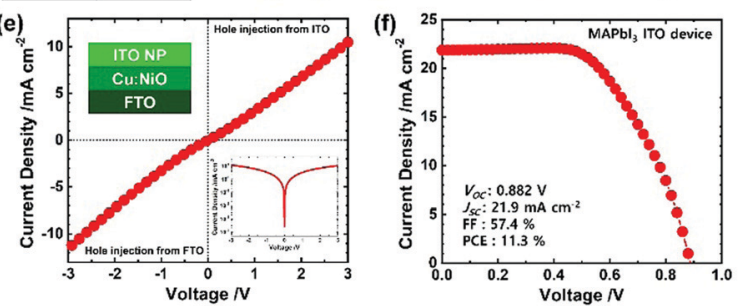

Fig. 2 (a) Schematic drawing and cross-sectional SEM image of a mesoscopic PSC incorporating an ITO electrode on top. The SEM image was taken following optimization. (b) Optical images taken before and after perovskite deposition showing a darker black from the substrate side than from the ITO side because of excellent infiltration. (c) Illustration of lead-free tin-based perovskite: white parts represent Schottky vacancies. (d) Diagram of energy levels for selective electron and hole extractions in PSC. (e) Linear $J-V$ curve of the hole-only device of ITO NP/Cu:NiO/FTO (inset: logarithmic J-V curve with symmetry). (f) Representative $J-V$ curve of $\mathrm{MAPb}_{3}$ ITO device measured under standard one-sun illumination.

the carbon devices; the results are shown in Fig. S3 and Table S2, ESI. $\dagger$ An incorporation of $\mathrm{EDAI}_{2}(0-20 \%)$ led to systematic alteration of the crystal structure and optical properties (Fig. S4, SEI) consistent with literature reports; ${ }^{26,53,54}$ the optimal $\operatorname{EDAI}_{2}(15 \%)$ decreased the $\mathrm{Sn}^{4+}$ defect states $>$ five-fold (XPS spectra, Fig. S5a and b, ESI $\dagger$ ). An energy-level diagram of the PSC sketched in Fig. 2d indicates the energetically aligned perovskite and ITO, where the perovskite energy levels including a band gap of $1.61 \mathrm{eV}$ were obtained according to the results shown in Fig. S4a and S5c, d. It is worth noting that ITO is a degenerate n-type semiconductor but it can efficiently extract holes from the perovskites, evidenced by a quasi ohmic $J-V$ behavior of the hole-only ITO device shown in Fig. 2e, via the formation of a recombination junction; ${ }^{55,56}$ the analogous interface is the ITO/PEDOT:PSS in the planar PSC. Meanwhile, despite pursuing scalable tin-based PSC herein, we have fabricated the mesoscopic ITO PSC with a lead perovskite (i.e., $\mathrm{MAPbI}_{3}$ ) to gain generality. The resulting power conversion efficiency (PCE) of $11.3 \%$ shown in Fig. $2 \mathrm{f}$ is comparable to that of the planar ITO PSC. ${ }^{57}$

To confirm the effects of the light reflectance, we applied ITO films of $1,2,4,6$ and 8 layers corresponding to the thicknesses of $2.1,4.2,7.8,11.0$ and $14.3 \mu \mathrm{m}$, respectively. Characteristic $J-V$ curves measured under one-sun illumination (AM 1.5G, $100 \mathrm{~mW} \mathrm{~cm}^{-2}$ ) are shown in Fig. 3a and Table S3 (ESI $\dagger$ ). The best PCE (4.4\%) resulted from four ITO layers. With increasing thickness of the ITO from 1 to 4 layers, the shortcircuit current $\left(\mathrm{J}_{\mathrm{SC}}\right)$ and fill factor $(\mathrm{FF})$ were enhanced from 15.1 to $16.7 \mathrm{~mA} \mathrm{~cm}{ }^{-2}$ and 42.4 to $55.6 \%$, respectively, while nearly maintaining an open-circuit voltage $\left(V_{\mathrm{OC}}\right)$ of $\sim 0.48 \mathrm{~V}$. As the cross-sectional SEM images (Fig. S6, ESI $\dagger$ ) display an excellent infiltration of the perovskite into $\mathrm{TiO}_{2} / \mathrm{Al}_{2} \mathrm{O}_{3}$ for one and two ITO layers, their decreased FF is associated with the relatively high sheet resistances (Table S1, ESI $\dagger$ ). The results of measurement of the spectra for the efficiency of conversion of the incident photons to current (IPCE) are shown in Fig. 3b: the integrated current densities from the IPCE match well with the $J_{\mathrm{SC}}$ from the measurement of $J-V$. The IPCE spectra track enhanced responses in the range of 380-800 $\mathrm{nm}$ with much greater response over the wavelengths beyond $600 \mathrm{~nm}$ with increasing thickness of ITO (i.e. increasing light reflection), accounting for the increased $J_{\mathrm{SC}}$ of the device with four ITO layers. Further increasing the thickness to 6 and 8 layers degraded all the photovoltaic performance. This effect is likely correlated with incomplete infiltration of the perovskite into the $\mathrm{TiO}_{2} / \mathrm{Al}_{2} \mathrm{O}_{3}$ layers, as shown in Fig. S6, ESI, $\dagger$ which impedes the light harvesting and charge collection to the $\mathrm{TiO}_{2}$.

The performance of the best device with four ITO layers was further improved on increasing the concentration of the precursor solution from 1 to $1.5 \mathrm{M}$, according to the results shown in Fig. S7a and Table S4, ESI. $\dagger$ The PCE attained 5.1\% at the perovskite concentration of $1.15 \mathrm{M}$ where the complete infiltration of the perovskite into $\mathrm{TiO}_{2} / \mathrm{Al}_{2} \mathrm{O}_{3}$ was realized (see Fig. 2a and Fig. S6c, ESI $\dagger$ ). The $J-V$ curves taken from the forward and reverse scan direction at the optimal condition are presented in Fig. S7b, ESI, $\dagger$ which shows a minor effect of hysteresis. To compare statistically the optimal condition with the former condition, we show histograms of photovoltaic parameters with 30 devices in Fig. 3c-f; the corresponding parameters are listed in Tables S5 and S6, ESI. $\dagger$ The optimal condition raised all the photovoltaic parameters with a narrow distribution: $V_{\mathrm{OC}}$ rose from $0.474 \pm 0.022$ to $0.491 \pm 0.018 \mathrm{~V} ; J_{\mathrm{SC}}$ rose from $16.1 \pm 1.5$ to $17.6 \pm 0.8 \mathrm{~mA} \mathrm{~cm}^{-2}$; FF rose from $54.7 \pm 3.0$ to $54.9 \pm 2.2 \%$; PCE hence rose from $4.1 \pm 0.4 \%$ to $4.7 \pm 0.3 \%$. Furthermore, the best ITO device attained a PCE of $5.4 \%$, which is the greatest among all-solution-processed lead-free PSCs. ${ }^{19,20,22,23,58,59}$
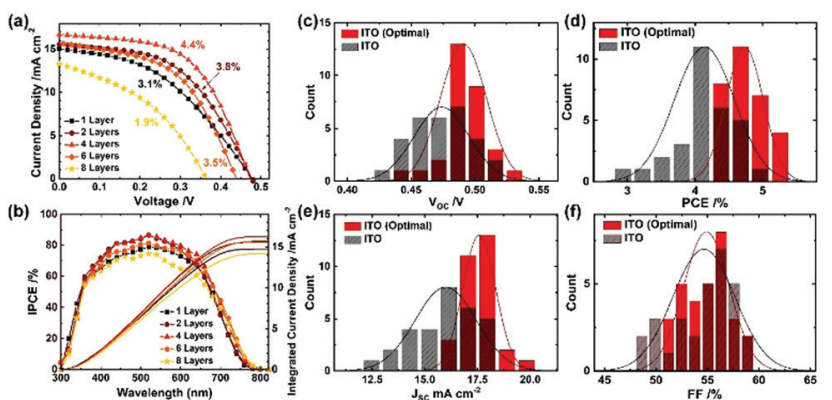

Fig. 3 (a) Representative $J-V$ curves measured under standard one-sun illumination and (b) IPCE spectra of ITO devices with varied layers. (c-f) Statistical histogram of 30 ITO devices each at non-optimal and optimal conditions; all photovoltaic parameters are improved concurrently with minimal spread following optimization. 

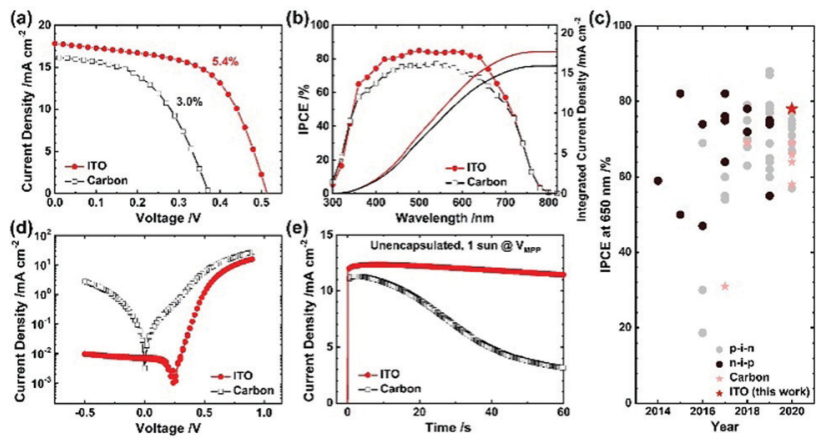

Fig. 4 Comparison of ITO and carbon devices. (a) $J-V$ curves measured under standard one-sun conditions. (b) IPCE spectra. (c) Evolution of IPCE (at $650 n m$ ) of the inverted $(p-i-n)$, regular $(n-i-p)$, carbon and ITO devices. (d) J-V curves measured under darkness. (e) Output current density measured under the standard one-sun conditions, at maximum power point and under ambient air.

The performance of the ITO device is also superior to those of the FA-based tin PSCs using Spiro-OMeTAD as the HTM (Table S7, ESI $\dagger$ ). Note that the back-contact electrodes of these regular planar or mesoscopic devices were made by thermal evaporation of silver metal under high vacuum condition limiting their future industrial scalability. While the planar devices adopt $\sim 200 \mathrm{~nm}$ thickness, closely associated with the effective charge diffusion length, for highperformance tin perovskites in solar cells, ${ }^{14,15,27,28,32-34,41}$ the $1 \mu \mathrm{m}$ thick $\mathrm{Al}_{2} \mathrm{O}_{3}$ insulating film in the mesoscopic devices is too harsh in terms of effective charge carrier diffusion for the tin perovskites. The further improvement in the PCE is likely made by decreasing the $\mathrm{Al}_{2} \mathrm{O}_{3}$ thickness.

Following the optimization, we compared the ITO device with the carbon device. The same experimental conditions except the $\sim 10 \mu \mathrm{m}$ thick carbon layer optimized in our earlier researches $^{20,23}$ was adopted for the carbon device. Even though carbon possesses a low sheet resistance of $26 \pm 1 \Omega \mathrm{sq} \cdot{ }^{-1}$, the PCE of ITO is nearly twice that of carbon (PCE 5.4\% for ITO $v s$. $3.0 \%$ for carbon), as shown in Fig. 4a (results summarized in Table S8, ESI $\dagger$ ). In the IPCE spectra, Fig. $4 \mathrm{~b}$, the integrated $J_{\mathrm{SC}}$ match the current densities of the $J-V$ curves for both the devices. The ITO device attained IPCE responses over $\sim 80 \%$ for the wavelength range of 400-650 $\mathrm{nm}$ and avoided significantly depressed responses beyond $650 \mathrm{~nm}$, an issue found in the mesoscopic tin PSC; the attained IPCE rivals that for the planar tin PSC, as shown in the IPCE evolution chart in Fig. 4c (details are summarized in Table S9, ESI $\dagger$ ). From the measured dark $J-V$ characteristic curves (Fig. 4 d), we found a significantly decreased charge recombination and charge injection barrier for the ITO device, representing superior catalytic activity for the ITO device than the carbon device. The results of electrochemical impedance spectroscopy (EIS), shown in Fig. S8, ESI, $\dagger$ indicate a greater charge-recombination resistance for the ITO device than for the carbon device (Table S10, ESI $\dagger$ ). The distinction in contact interface - the seamless contact of $\mathrm{Al}_{2} \mathrm{O}_{3} /$ ITO compared to the partly disjointed contact of $\mathrm{Al}_{2} \mathrm{O}_{3}$ / carbon creating the vacant spaces (i.e., no perovskite filled) ${ }^{20}$ would be responsible for the recombination. Combined with the light reflectivity, the excellent interfacial properties account for the significantly greater device performance of the ITO than that of the carbon.

As carbon is a member of a highly stable class of materials explored in diverse applications, ${ }^{39,60,61}$ comparing ITO with carbon can offer deep insight into operational stability. We thus compared the ITO device with the carbon device under three conditions: (i) un-encapsulated devices under one-sun illumination at the maximum power point (Fig. 4e) (ii) encapsulated devices in darkness (Fig. S9a, ESI $\dagger$ ) and (iii) encapsulated devices under one-sun illumination (Fig. S9b, ESI $\dagger$ ). It is well known that the tin perovskites suffer from unwanted rapid oxidation of $\mathrm{Sn}^{2+}$ to $\mathrm{Sn}^{4+}$ by water and oxygen, and in the carbon or ITO devices, tin perovskites can meet oxygen and gaseous molecular water diffused through the mesoporous ITO or carbon. Under the first condition, ITO showed nearly no decay (96\% retention) whereas carbon displayed a rapid decay ( $28 \%$ retention) within $60 \mathrm{~s}$. It is reasonable to infer that ITO is able to better protect the tin perovskite against oxygen and water in large due to the seamless contact between ITO and $\mathrm{Al}_{2} \mathrm{O}_{3}$ minimizing the exposure of the perovskite to ambient condition unlike the carbon $/ \mathrm{Al}_{2} \mathrm{O}_{3}$ contact. ${ }^{20}$ Under the second condition, $>90 \%$ retention of the initial PCE was attained for ITO, better than for carbon ( $>70 \%$ retention) for an enduring period $>1000 \mathrm{~h}$. Under the third condition, both the devices displayed a slight decrease for an initial $\sim 500 \mathrm{~s}$ but the PCE of the ITO device gradually increased (to $107 \%$ retention) whereas that of the carbon device constantly attenuated (81\% retention) for $2 \mathrm{~h}$. The device degradation under these conditions might arise from an unavoidable minute amount of water or oxygen present even after encapsulation. Despite this, the ITO device greatly suppressed the degradation for long periods unlike the carbon device, representing excellent stability by protecting the tin perovskite. Regardless of the measurement conditions, all results are consistent, and indicate that the ITO device can offer greater stability than the carbon device.

\section{Conclusions}

In conclusion, we have developed solution-processable ITO nanoparticulate electrodes to replace carbon electrodes in mesoscopic hybrid tin-based PSCs. The ITO device showed distinctive improvements over the carbon device with respect to light reflection, hole selectivity, device performance and stability. Unlike carbon, ITO has increased visible light reflectance with increasing film thickness. As a result, a PCE of 5.4\% (cf. $3.0 \%$ for carbon) was attained, which is a record efficiency for a lead-free all-solution-processed PSC. The ITO device also demonstrated operational stability under darkness and lightsoaking conditions greater than that of carbon, demonstrating $>90 \%$ retention of the initial output compared to $30-80 \%$ retention for carbon. These remarkable optical properties together with the superior device performance make the ITO device a promising candidate for future applications, such as indoor devices in dim light and tandem solar cells or tandem hybrids. 


\section{Conflicts of interest}

There are no conflicts to declare.

\section{Acknowledgements}

Taiwan Ministry of Science and Technology (grant MOST 108-2119M-009-004) and Centre for Emergent Functional Matter Science of National Chiao Tung University from The Featured Areas Research Centre Program within the framework of the Higher Education SPROUT Project by Taiwan Ministry of Education provided financial support of this research. National Synchrotron Radiation Research Centre, Hsinchu Science Park, Taiwan, provided beam time for measurements of UPS.

\section{References}

1 Certified Best Cell Efficiency from NREL, https://www.nrel. gov/pv/assets/pdfs/best-research-cell-efficiencies.20200406. pdf.

2 A. Kojima, K. Teshima, Y. Shirai and T. Miyasaka, J. Am. Chem. Soc., 2009, 131, 6050-6051.

3 H.-S. Kim, C.-R. Lee, J.-H. Im, K.-B. Lee, T. Moehl, A. Marchioro, S.-J. Moon, R. Humphry-Baker, J.-H. Yum, J. E. Moser, M. Grätzel and N.-G. Park, Sci. Rep., 2012, 2, 591.

4 M. M. Lee, J. Teuscher, T. Miyasaka, T. N. Murakami and H. J. Snaith, Science, 2012, 338, 643-647.

5 J.-P. Correa-Baena, M. Saliba, T. Buonassisi, M. Grätzel, A. Abate, W. Tress and A. Hagfeldt, Science, 2017, 358, 739-744.

6 M. Saliba, T. Matsui, J.-Y. Seo, K. Domanski, J.-P. CorreaBaena, M. K. Nazeeruddin, S. M. Zakeeruddin, W. Tress, A. Abate, A. Hagfeldt and M. Grätzel, Energy Environ. Sci., 2016, 9, 1989-1997.

7 Y. Rong, Y. Hu, A. Mei, H. Tan, M. I. Saidaminov, S. Il Seok, M. D. McGehee, E. H. Sargent and H. Han, Science, 2018, 361, eaat8235.

8 K. Yoshikawa, H. Kawasaki, W. Yoshida, T. Irie, K. Konishi, K. Nakano, T. Uto, D. Adachi, M. Kanematsu, H. Uzu and K. Yamamoto, Nat. Energy, 2017, 2, 17032.

9 W. Ke and M. G. Kanatzidis, Nat. Commun., 2019, 10, 965.

10 D. B. Mitzi, C. D. Dimitrakopoulos and L. L. Kosbar, Chem. Mater., 2001, 13, 3728-3740.

11 A. Waleed, M. M. Tavakoli, L. Gu, Z. Wang, D. Zhang, A. Manikandan, Q. Zhang, R. Zhang, Y.-L. Chueh and Z. Fan, Nano Lett., 2017, 17, 523-530.

12 W.-L. Hong, Y.-C. Huang, C.-Y. Chang, Z.-C. Zhang, H.-R. Tsai, N.-Y. Chang and Y.-C. Chao, Adv. Mater., 2016, 28, 8029-8036.

13 G. Xing, M. H. Kumar, W. K. Chong, X. Liu, Y. Cai, H. Ding, M. Asta, M. Grätzel, S. Mhaisalkar, N. Mathews and T. C. Sum, Adv. Mater., 2016, 28, 8191-8196.

14 S. Shao, J. Liu, G. Portale, H.-H. Fang, G. R. Blake, G. H. ten Brink, L. J. A. Koster and M. A. Loi, Adv. Energy Mater., 2018, 8, 1702019.

15 K. Nishimura, M. A. Kamarudin, D. Hirotani, K. Hamada, Q. Shen, S. Iikubo, T. Minemoto, K. Yoshino and S. Hayase, Nano Energy, 2020, 74, 104858.
16 Z. Zhao, F. Gu, Y. Li, W. Sun, S. Ye, H. Rao, Z. Liu, Z. Bian and C. Huang, Adv. Sci., 2017, 4, 1700204.

17 H. Xu, Y. Jiang, T. He, S. Li, H. Wang, Y. Chen, M. Yuan and J. Chen, Adv. Funct. Mater., 2019, 29, 1807696.

18 P. Li, X. Liu, Y. Zhang, C. Liang, G. Chen, F. Li, M. Su, G. Xing, X. Tao and Y. Song, Angew. Chem., Int. Ed., 2020, 59, 6909-6914.

19 M. Chen, M.-G. Ju, M. Hu, Z. Dai, Y. Hu, Y. Rong, H. Han, X. C. Zeng, Y. Zhou and N. P. Padture, ACS Energy Lett., 2019, 4, 276-277.

20 C.-M. Tsai, Y.-P. Lin, M. K. Pola, S. Narra, E. Jokar, Y.-W. Yang and E. W.-G. Diau, ACS Energy Lett., 2018, 3, 2077-2085.

21 W. Li, J. Li, J. Li, J. Fan, Y. Mai and L. Wang, J. Mater. Chem. A, 2016, 4, 17104-17110.

22 C. M. Tsai, N. Mohanta, C. Y. Wang, Y. P. Lin, Y. W. Yang, C. L. Wang, C. H. Hung and E. W. G. Diau, Angew. Chem., Int. Ed., 2017, 56, 13819-13823.

23 M. Rameez, E. Y.-R. Lin, P. Raghunath, S. Narra, D. Song, M.-C. Lin, C.-H. Hung and E. W.-G. Diau, ACS Appl. Mater. Interfaces, 2020, 12, 21739-21747.

24 M. H. Kumar, S. Dharani, W. L. Leong, P. P. Boix, R. R. Prabhakar, T. Baikie, C. Shi, H. Ding, R. Ramesh, M. Asta, M. Graetzel, S. G. Mhaisalkar and N. Mathews, Adv. Mater., 2014, 26, 7122-7127.

25 E. Jokar, C.-H. Chien, A. Fathi, M. Rameez, Y.-H. Chang and E. W.-G. Diau, Energy Environ. Sci., 2018, 11, 2353-2362.

26 W. Ke, C. C. Stoumpos, M. Zhu, L. Mao, I. Spanopoulos, J. Liu, O. Y. Kontsevoi, M. Chen, D. Sarma, Y. Zhang, M. R. Wasielewski and M. G. Kanatzidis, Sci. Adv., 2017, 3, e1701293.

27 T. Nakamura, S. Yakumaru, M. A. Truong, K. Kim, J. Liu, S. Hu, K. Otsuka, R. Hashimoto, R. Murdey, T. Sasamori, H. Do Kim, H. Ohkita, T. Handa, Y. Kanemitsu and A. Wakamiya, Nat. Commun., 2020, 11, 3008.

28 C. Wang, F. Gu, Z. Zhao, H. Rao, Y. Qiu, Z. Cai, G. Zhan, X. Li, B. Sun, X. Yu, B. Zhao, Z. Liu, Z. Bian and C. Huang, Adv. Mater., 2020, 32, 1907623.

29 Q. Tai, X. Guo, G. Tang, P. You, T.-W. Ng, D. Shen, J. Cao, C.-K. Liu, N. Wang, Y. Zhu, C.-S. Lee and F. Yan, Angew. Chem., Int. Ed., 2019, 58, 806-810.

30 X. Meng, J. Lin, X. Liu, X. He, Y. Wang, T. Noda, T. Wu, X. Yang and L. Han, Adv. Mater., 2019, 31, 1903721.

31 S. J. Lee, S. S. Shin, Y. C. Kim, D. Kim, T. K. Ahn, J. H. Noh, J. Seo and S. Il Seok, J. Am. Chem. Soc., 2016, 138, 3974-3977.

32 X. Liu, Y. Wang, T. Wu, X. He, X. Meng, J. Barbaud, H. Chen, H. Segawa, X. Yang and L. Han, Nat. Commun., 2020, 11, 2678.

33 F. Wang, X. Jiang, H. Chen, Y. Shang, H. Liu, J. Wei, W. Zhou, H. He, W. Liu and Z. Ning, Joule, 2018, 2, 2732-2743.

34 X. Jiang, F. Wang, Q. Wei, H. Li, Y. Shang, W. Zhou, C. Wang, P. Cheng, Q. Chen, L. Chen and Z. Ning, Nat. Commun., 2020, 11, 1245.

35 C. Liu, J. Tu, X. Hu, Z. Huang, X. Meng, J. Yang, X. Duan, L. Tan, Z. Li and Y. Chen, Adv. Funct. Mater., 2019, 29, 1808059. 
36 W. Ke, C. C. Stoumpos, J. L. Logsdon, M. R. Wasielewski, Y. Yan, G. Fang and M. G. Kanatzidis, J. Am. Chem. Soc., 2016, 138, 14998-15003.

37 X. Liu, Y. Wang, F. Xie, X. Yang and L. Han, ACS Energy Lett., 2018, 3, 1116-1121.

38 A. Mei, X. Li, L. Liu, Z. Ku, T. Liu, Y. Rong, M. Xu, M. Hu, J. Chen, Y. Yang, M. Grätzel and H. Han, Science, 2014, 345, 295-298.

39 H. Chen and S. Yang, Adv. Mater., 2017, 29, 1603994.

40 L. Qiu, S. He, L. K. Ono, S. Liu and Y. Qi, ACS Energy Lett., 2019, 4, 2147-2167.

41 E. Jokar, C.-H. Chien, C.-M. Tsai, A. Fathi and E. W.-G. Diau, Adv. Mater., 2019, 31, 1804835.

42 Y. Zhang, S.-W. Ng, X. Lu and Z. Zheng, Chem. Rev., 2020, 120, 2049-2122.

43 H. C. Hulst and H. C. van de Hulst, Light scattering by small particles, Courier Corporation, 1981.

44 Q. Zhang, D. Myers, J. Lan, S. A. Jenekhe and G. Cao, Phys. Chem. Chem. Phys., 2012, 14, 14982-14998.

45 R. Prasanna, T. Leijtens, S. P. Dunfield, J. A. Raiford, E. J. Wolf, S. A. Swifter, J. Werner, G. E. Eperon, C. de Paula, A. F. Palmstrom, C. C. Boyd, M. F. A. M. van Hest, S. F. Bent, G. Teeter, J. J. Berry and M. D. McGehee, Nat. Energy, 2019, 4, 939-947.

46 K. P. Marshall, M. Walker, R. I. Walton and R. A. Hatton, Nat. Energy, 2016, 1, 16178.

47 S. Ghanizadeh, T. A. N. Peiris, D. S. Y. Jayathilake, D. A. Hutt, K. G. U. Wijayantha, D. J. Southee, P. P. Conway, P. Marchand, J. A. Darr, I. P. Parkin and C. J. Carmalt, Ceram. Int., 2016, 42, 18296-18302.
48 Z. Song, S. C. Watthage, A. B. Phillips and M. J. Heben, J. Photonics Energy, 2016, 6, 1-23.

49 W. Gao, C. Chen, C. Ran, H. Zheng, H. Dong, Y. Xia, Y. Chen and W. Huang, Adv. Funct. Mater., 2020, 30, 2000794.

50 J. Lee, S. Lee, G. Li, M. A. Petruska, D. C. Paine and S. Sun, J. Am. Chem. Soc., 2012, 134, 13410-13414.

51 Z. Chen, W. Li, R. Li, Y. Zhang, G. Xu and H. Cheng, Langmuir, 2013, 29, 13836-13842.

52 G. Bühler, D. Thölmann and C. Feldmann, Adv. Mater., 2007, 19, 2224-2227.

53 W. Ke, P. Priyanka, S. Vegiraju, C. C. Stoumpos, I. Spanopoulos, C. M. M. Soe, T. J. Marks, M.-C. Chen and M. G. Kanatzidis, J. Am. Chem. Soc., 2018, 140, 388-393.

54 S. Vegiraju, W. Ke, P. Priyanka, J.-S. Ni, Y.-C. Wu, I. Spanopoulos, S. L. Yau, T. J. Marks, M.-C. Chen and M. G. Kanatzidis, Adv. Funct. Mater., 2019, 29, 1905393.

55 M. De Bastiani, A. S. Subbiah, E. Aydin, F. H. Isikgor, T. G. Allen and S. De Wolf, Mater. Horiz., 2020, 7, 2791-2809. 56 J. Meyer, S. Hamwi, M. Kröger, W. Kowalsky, T. Riedl and A. Kahn, Adv. Mater., 2012, 24, 5408-5427.

57 Z. Zhou and S. Pang, J. Mater. Chem. A, 2020, 8, 503-512.

58 J. Shin, M. Kim, S. Jung, C. S. Kim, J. Park, A. Song, K.-B. Chung, S.-H. Jin, J. H. Lee and M. Song, Nano Res., 2018, 11, 6283-6293.

59 T. Zhang, H. Li, H. Ban, Q. Sun, Y. Shen and M. Wang, J. Mater. Chem. A, 2020, 8, 4118-4124.

60 K. Fu, Y. Yao, J. Dai and L. Hu, Adv. Mater., 2017, 29, 1603486.

61 L. Fagiolari and F. Bella, Energy Environ. Sci., 2019, 12, 3437-3472. 